\title{
Às PESQUISADORAS DO CAMPO AYAHUASQUEIRO: DIFICULDADES E POTENCIALIDADES (BRASIL - PERU)
}

\author{
ANA GRETEL ECHAZÚ BÖSCHEMEIER ${ }^{1}$ \\ CAMILA DE PIERI BENEDITO²
}

\begin{abstract}
RESUMO
Através da revisão crítica de nossas experiências etnográficas no Brasil e no Peru, o presente artigo expõe as dificuldades e os riscos que investigadoras podem enfrentar em campo nos círculos ayahuasqueiros, as potencialidades de seus trabalhos e, ao final, algumas recomendações para as pesquisadoras. Com um propósito que é tanto metodológico como pedagógico, nossas recomendações levam em consideração as especificidades de campos que envolvem o uso ritual da ayahuasca em cenários marcados por lideranças tradicionais, políticas e espirituais reconhecidamente masculinas.
\end{abstract}

PALAVRAS-CHAVE

Gênero; Sexualidades; Trabalho de campo; Dificuldades; Psicoativos; Ayahuasca.

\section{WOMEN RESEARCHERS IN THEAYAHUASCA FIELD: DifFICULTIES AND POTENTIALITIES (BRAZIL - PERU)}

\begin{abstract}
Guided by a methodological and pedagogical interest, this proposal takes into consideration the difficulties and risks that female researchers may face during fieldwork within ayahuasca circles. Thus, the text suggestts some working strategies which can be useful in those contexts. We critically review our own experiences during our distinctive researches in Brazil and Peru, debating the fields' specificities regarding the ritual use of ayahuasca on scenarios shaped by traditional, political and spiritual admittedly masculine authorities.
\end{abstract}

\section{KEYWORDS}

Gender; Sexualities; Fieldwork; Difficulties; Psychoactives; Ayahuasca.

\section{POUR DES CHERCHEUSES DE CHAMP D'ÉTUDE D'AYAHUASCA: DIFFICULTÉSET POTENCIELS (BRÉSIL - PÉROU)}

\begin{abstract}
1 Professora Adjunta do Departamento de Antropologia da UFRN. Doutora em Antropologia pela Universidade de Brasília com pesquisa financiada pela Capes e FAP-DF. Dedico este trabalho a Eduardo Maranhão, Dávila da Cruz Andrade e Maíra de Oliveira Dias, agradecendo pela experiência ímpar da ABHR - João Pessoa 2019, assim como a Leilane Assunção (in memoriam), Leuça Teixeira, Juliana Trevas, Jaína Alcântara e às mulheres e pessoas não binárias que encarnam a luta antiproibicionista com tanta solidez acadêmica e coragem existencial - e que, caminhando, ensinam a caminhar. Finalmente, agradeço a orientação da profa. Soraya Fleischer durante a pesquisa de doutorado aqui referida. Com seu acompanhamento lúcido e afetuoso ela me ajudou a atravessar as não poucas dificuldades do campo e a elaborar as ferramentas que hoje compõem minha prática profissional.
\end{abstract}

${ }^{2}$ Doutora em Sociologia pela Universidade Federal de São Carlos, com pesquisa financiada pela Capes. 


\section{RÉSUMÉ}

À travers la révision critique sur notres éxpériences ethnographiques au Brésil et au Pérou, le présent article expose les difficultés et les risques que des chercheuses peuvent confronter dans les sites de recherche aux cercles d'ayahuasca, les potentialités de ses travails et, enfin, quelques recommendations pour les chercheuses. Avec un but qui est autant méthodologique que pédagogique, notres recommendations prendent en considération les spécificités des champs d'étude qui concernent l'utilisation rituelle d'ayahuasca dans des milieux, traditionnellement, politiquement et spirituellement, marqués par des dirigeants masculins.

\section{MOTS-CLÉS}

Genre; Sexualitées; Travail de terrain; Difficultés; Psychoactifs; Ayahuasca.

\section{A LAS INVESTIGADORES DEL CAMPO AYAHUASQUERO: DIFICULTADES Y POTENCIALIDADES (BRASIL - PERÚ)}

\section{RESUMEN}

A través de la revisión crítica de nuestras experiencias etnográficas de doctorado en Brasil y en Perú, el presente artículo expone las dificultades y los riesgos que investigadoras pueden enfrentar en el campo de los círculos ayahuasqueros, las potencialidades de sus trabajos $y$, al final, algunas recomendaciones de trabajo orientadas hacia las investigadoras. Con un propósito que es tanto metodológico como pedagógico, nuestras recomendaciones llevan en consideración las especificidades de campos que involucran el uso ritual de la ayahuasca en esenarios marcados por liderazgos tradicionales, políticos y espirituales reconocidamente masculinos.

\section{Palabras Clave}

Género; Sexualidades; Trabajo de campo; Dificultades; Psicoactivos; Ayahuasca. 


\title{
INTRODUÇÃO
}

\begin{abstract}
"O poder parecia ser mais do que uma permuta entre sujeitos ou uma relação de inversão constante entre um sujeito e um Outro; na verdade, o poder parecia operar na própria produção dessa estrutura binária em que se pensa o conceito de gênero" (BUTLER, 2003, p.6).
\end{abstract}

No presente artigo, partimos da inquietação que corresponde à existência de estruturas de gênero pouco discutidas, tanto nas pesquisas quanto nas situações cotidianas dos circuitos ayahuasqueros, as quais condicionam e muitas vezes determinam e cerceiam experiências com potência libertadora, tal como são as vivências com ayahuasca.

Desde o lugar de alteridade que ocupamos e que nos distancia, de forma inevitável, do "monopólio masculino" a respeito do manejo da ayahuasca nos mais diversos contextos (COLPRON, 2005), apresentamos aqui nossas experiências etnográficas em espaços ayahuasqueiros do Brasil e do Peru e elaboramos algumas propostas metodológicas para as pesquisadoras que trabalham nesses contextos. Рara tanto, debatemos os riscos e as dificuldades da experiência de campo, como também as potencialidades das pesquisas feitas por mulheres e pessoas LGBTQI+s. Ainda refletimos sobre as especificidades das pesquisas nesses espaços, caracterizados pelo uso ritual de uma bebida psicoativa ${ }^{3}$ em grupos que estão, na maior parte das vezes, centralizados em lideranças reconhecidamente masculinas.

No decorrer do artigo, tocaremos as limitações e as vulnerabilidades que nós mulheres brancas, não heteronormativas e acadêmicas - experienciamos durante nossas pesquisas. Nosso ponto de partida foi um texto de divulgação sobre violência sexual e políticas de gênero no campo ayahuasqueiro que escrevemos em 2018 (ECHAZú BÖSCHEMEIER; BENEDITO, 2018a; 2018b; 2018c) expondo, a partir de denúncias elaboradas por um coletivo de mulheres brasileiras, três casos de abusos que tiveram ampla divulgação naquele ano, dois deles dentro do campo ayahuasqueiro ${ }^{4}$.

Foi no espaço dessa escrita/meditação conjunta que trocamos experiências etnográficas e tratamos das situações tensas, conflitivas e/ou violentas que vivenciamos durante nossos trabalhos de campo. A troca gerou uma vontade de escrever algo maior que não apenas se colocasse como denúncia, mas também como reflexão epistemológica, metodológica e pedagógica no interior do campo de estudos sobre práticas e espaços vinculados à ayahuasca na América Latina.

\footnotetext{
${ }^{3}$ Nos referimos como "campo ayahuasqueiro" àquele vinculado ao consumo ritual da ayahuasca. Usualmente, a bebida ayahuasca é resultado da decocção do cipó jagube (Banisteriopsis caapi) com a folha da chacrona (Psychotria viridis).

${ }^{4}$ Naquela matéria observamos esses casos extremos de violência sexual como reflexo das desigualdades de gênero na sociedade brasileira. Isso pois, como tais comunidades estavam hierarquicamente organizadas e o poder político e espiritual estava centralizado nessas lideranças masculinas, os abusos não se relacionam ao uso da ayahuasca ou a aspectos próprios da religiosidade ritual, mas sim a uma estrutura social que apoia as desigualdades de gênero.
} 
Temos observado que, apesar do campo ayahuasqueiro ser marcado pela presença majoritária de líderes homens e pelo apagamento de sexualidades não normativas, pouco é falado sobre gênero e sexualidades na bibliografia especializada ${ }^{5}$. Consideramos que a presença de mulheres e LGBTQI+s ${ }^{6}$ na função de pesquisadoras tem como potencialidade o alavancamento de iniciativas que reflitam esses temas desde a especificidade narrativa que parte da experiência corporal no mundo.

Falamos aqui de gênero a partir das contribuições da filósofa Judith Butler (2003) e, portanto, pensamos "gênero", "feminino" e "masculino" como efeitos de um discurso sobre corpos biológicos, fabricando uma fantasia sobre eles, então reforçada pela contínua performance da feminilidade, da masculinidade e da heterossexualidade compulsória. Assim, não refletimos sobre o que observamos em campo como sendo do âmbito da natureza, do instinto, da espiritualidade, ou da essência, mas como uma produção sobre os corpos que pode ser historicizada, questionada e criticada.

Por fim, vale destacar que este artigo toca em um tema pouco debatido. Trabalhos se produzem, pesquisas se publicam, conhecimentos se consolidam, mas desconhecemos a que custo. Esperamos que pesquisadoras vindas das mais diversas áreas do conhecimento e da prática profissional possam se aproveitar das considerações que apresentaremos para realizarem suas pesquisas no campo ayahuasqueiro de forma satisfatória, tanto no que condiz à produção de conhecimento sobre o tema, quanto para elas enquanto seres no mundo.

\section{PERU: TURISMO XAMÂNICO}

O turismo xamânico na Amazônia peruana tem se desenvolvido a partir de um modelo de uso "tradicional, terapêutico e espiritual". Na atualidade, há nas principais cidades da selva peruana (Iquitos, Madre de Dios, Tarapoto, Pucallpa, Moyobamba) dezenas de xamãs, curandeiros ou vegetalistas que trabalham com plantas que atendem a comunidade e aos chamados "turistas xamânicos" (LABATE, 2004; ECHAZÚ BÖSCHEMEIER, 2015). Porém, são poucos os que possuem seus próprios centros de tratamento com ayahuasca.

\footnotetext{
${ }^{5}$ Já observamos isso em outros trabalhos: COLPRON (2005); ECHAZÚ BÖSCHEMEIER (2015; 2018); BENEDITO (2019). Uma exceção é representada pelo recente e pioneiro movimento Queering Psychedelics nos Estados Unidos (LABATE, 2019).

6 Salientamos que, embora tenhamos planejado essa empreitada para o futuro, não nos aprofundaremos na abordagem interseccional neste artigo. Pontuamos que esse tipo de análise deva ser estimulada através da produção de mais trabalhos etnográficos que partam de olhares situados desde corporalidades diversas, especialmente daquelas que têm sido historicamente colocadas às margens da produção de ciência - pessoas negras, indígenas, quilombolas, jovens, com deficiência, etc. Esperamos que o presente artigo constitua um estímulo para a concretização narrativa desses "lugares de fala" (RIBEIRO, 2017).
} 
Meu trabalho de campo foi iniciado em centros que, segundo fui descobrindo, estavam bastante institucionalizados. Com o passar do tempo, fui reconhecendo as margens desses espaços, e foi nelas que finalmente a minha tese de doutorado se desenvolveu (ECHAZÚ BÖSCHEMEIER, 2015). No que segue, analisarei a minha experiência em um dos centros ayahuasqueiros localizados na Amazônia Peruana e mais conhecidos no nível regional, nacional e internacional, cuja especificidade guardarei nesse artigo.

O centro escolhido para a presente análise emerge como modelo de tratamento às "dependências" que tem sido referência para outros que posteriormente se estabeleceram na região e no restante da América Latina, replicado inclusive, com suas especificidades, no Brasil (MERCANTE, 2013). No centro etnografado, direcionado ao tratamento de todo tipo de conduta compulsória ou abusiva, se desenvolvem três atividades icônicas dentro do modelo de tratamento agenciado como propriamente amazônico: dietas, purgas e cerimônias com ayahuasca. Esses três procedimentos medulares se encontram fortemente relacionadas entre si e são praticados de forma corriqueira em todos os espaços terapêuticorituais visitados durante o trabalho de campo, que percorreu várias cidades amazônicas?

O espaço no qual se focaliza a presente análise crítica conta com a colaboração de médicos/as, psicólogos/as, enfermeiros/as, professores/as de yoga e de biodança, assim como pessoal administrativo. Neste espaço institucionalizado, que prepara a decocção para seu consumo - pago à maneira de um centro médico particular - , a entidade da ayahuasca é referenciada a partir de duas figuras femininas, maternais e frequentemente fundidas: a da Pachamama - compreendida como a "mãe terra" dentro de um modelo indígena andino, e a da Virgem Maria, que se situa dentro do modelo "cristão popular" amazônico.

O centro realiza as cerimônias com ayahuasca periodicamente e, de forma mais ou menos fixa, entre uma ou duas vezes por semana. Para além das internações neste espaço, o serviço é comercializado externamente, sendo cobrado um preço particular por dieta, purga ou cerimônia com ayahuasca. O modelo de tratamento proposto está baseado na limpeza física, psíquica e espiritual e se apresenta como "tradicionalmente amazônico", apesar de seu caráter higienizado a respeito das práticas de bruxaria, como veremos mais à frente. Ali se

7 As dietas são atividades terapêuticas que se encontram atravessadas por olhares e performatividades de gênero, e que se viram transformadas nos últimos anos com as mudanças impostas pela urbanização e a mercantilização dos entornos indígenas. Em certos contextos, de serem restritivas para homens, passaram a serem permitidas para mulheres. Em outros, a menstruação das mulheres é um momento que não se encontra no foco da interdição ritual: isto é, mulheres menstruadas podem, da mesma forma em que qualquer outro ser humano adulto, dietar. Para mais referências sobre essas transformações, podem ser consultados os textos de Gearin \& Labate (2018) e Platero (2018).

${ }^{8}$ Através de trabalhos escritos sobre a ayahuasca (BENEDITO, 2019; FERREIRA, 2008; GOULART, 2004) e de nossas pesquisas de campo, pudemos observar o paradoxo de que a ayahuasca seja relacionada a "forças" ou "entidades" femininas, enquanto que manipulada por identidades masculinas. 
oferece a possibilidade de internação de pessoas que se reconhecem como "viciadas em drogas" ou, em falas mais formais, "compulsivas e dependentes" - em relação a substâncias ou algum outro tipo de comportamento, como "ludopatas" e "sexopatas".

No centro não é permitida a internação de mulheres. Durante os nove meses nos quais os pacientes homens permanecem internados e em tratamento lhes é proibido ter intercurso sexual. "Mas porque se optou por tratar homens, e não mulheres?", perguntei a um psicoterapeuta da equipe. "Elas eram incompatíveis com os homens", ele me respondeu e continuou: "Tivemos problemas com as mulheres. Eram histéricas, problemáticas e difíceis de controlar. Teve casos de mulheres que tiveram relações [sexuais] com homens aqui dentro do centro, isso interrompeu todo o tratamento deles". É interessante notar que tal argumento, além de colocar a responsabilidade da quebra da regra relativa à abstinência sexual somente nas mulheres, também ignora a possibilidade de relações entre homens como se fosse somente possível o intercurso heterossexual.

Havia uma série de restrições e formas de controle orientadas às poucas mulheres que faziam parte da equipe do centro: quando menstruadas, eram impedidas de realizar dietas ou cerimônias com ayahuasca e de conviverem com as pessoas que participam dessas atividades. Da mesma maneira, as terapeutas mulheres, uma verdadeira minoria na equipe, eram orientadas a não irem ao trabalho durante os dias em que estavam menstruadas. A explicação oficialmente dada era a necessidade da manutenção de um tabu tido como próprio do campo amazônico ayahuasqueiro. Entretanto, ao longo da minha pesquisa de campo, foi possível contrastar esse imaginário bastante difundido com as experiências narradas por curandeiras que trabalhavam de forma autônoma em seus próprios espaços, onde elas mesmas e outras mulheres menstruantes e inclusive gestantes ou que amamentavam, bebiam ayahuasca. Elas conheciam a regra, porém a aplicavam em certos contextos ou não a achavam tão importante dentro das suas práticas (ECHAZú BÖSCHEMEIER, 2015).

Durante o trabalho de campo, eu aproveitava meu tempo fora do centro para prestar ouvidos às interpretações alternativas àquelas "oficiais" - isto é, aquelas enunciadas dentro da instituição. Uma dessas interpretações veio de um jovem que já foi paciente internado no referido espaço. Respondendo à pergunta sobre por que o centro escolheu trabalhar com homens e não com mulheres, ele me disse que "eram mais homens do que mulheres os que precisam de um tratamento para saírem das drogas". Outra hipótese que circulava estava centrada nos xamãs. Segundo um dos pacientes lá internados, de origem argentina, o fato de os xamãs serem sobretudo homens tornava o modelo mais "compatível" para todos, pois estaria baseado em homens tratando outros homens.

\footnotetext{
${ }^{9}$ Pessoas que seriam viciadas em jogos e em sexo, respectivamente.
} 
Quando finalmente consegui formalizar uma entrevista na sala do diretor da instituição, manifestei a ele meu desejo de realizar trabalhos voluntários no centro. Sua resposta, porém, foi contundente: "o inferno está cheio de boas intenções". Em seguida, ele ainda pontuou como deveria acontecer meu trabalho de campo naquele local. Eu como "mulher jovem" deveria visitar o centro com roupas que não fossem "provocativas", pois os pacientes lá internados "não tinham visto nem tocado mulher nenhuma" há um tempo considerável, estando em abstinência sexual há meses. No dizer do diretor, os pacientes do centro também estavam tomando plantas maestras que podiam ter efeito afrodisíaco, piorando, para meu pesar e o deles, a situação. Nessa visão, os pacientes se tornariam "incontroláveis" perante a visão de uma mulher jovem, e vítimas inexoráveis da sua sedução.

Na minha experiência de contato direto com pacientes do centro, nenhum desses desconfortos teve lugar. Tive a possibilidade de visitar o espaço onde moravam, participar de um momento de ócio enquanto um dos pacientes fazia massagens em outro - contradizendo as orientações individuais de "desintoxicação" dos aspectos sensuais da sociabilidade entre pessoas -, assim como pude conversar de forma amena com homens que vinham de partes diversas: da periferia de Lima, do sul da Argentina, da França urbana, da amazônica cidade de Tarapoto. Observei essas pessoas empenhadas em meditar sobre suas vidas e abertas para compartilhar insights, em um momento certamente especial onde as conversas tendiam a ser bastante reflexivas. Mas não aconteceu a mesma conexão com os profissionais do centro.

Assim, ainda que o trabalho de voluntariado não tenha sido aprovado pela direção, tive a autorização para realizar visitas não formais no espaço, que me propiciaram participar inclusive de reuniões grupais. Na minha tentativa de "acesso discreto", usei o serviço de um tratamento purgante comercializado pelo centro e passei a organizar uma oficina sobre antropologia do corpo e da saúde com um grupo de cinco pacientes - evidentemente, homens.

As questões relativas à sexualidade costumavam ser colocadas do lado da interdição. Se enfatizava a importância de uma conduta sexual vinculada à abstinência por parte do curandeiro, e também a abstinência sexual daqueles/as que participassem em dietas ou purgas, com a finalidade de manter uma espécie de fronteira do próprio corpo frente a relações que sujam. Isso acontecia paralelamente com as recomendações de abstinência de determinadas comidas, como frituras e carne de porco, assim como do uso de perfumes e da fala em determinados momentos.

Tardei um bom tempo em descobrir que aquele espaço que se projetava como exemplo de tratamento intercultural por meio do uso de terapias com plantas estava enraizado em uma estrutura formulada por homens e para homens. O tempo que passei acompanhando as atividades do centro me trouxe não poucas frustrações neste aspecto. Percebi que havia um limite, uma impossibilidade de acessar a uma experiência colocada 
tanto pela mídia quanto pela literatura especializada como "única no mundo" e terapeuticamente inovadora (DEMANGE, 2002), pois era um espaço cuja organização se centrava na heteronormatividade compulsória, por uma parte, e excluía às mulheres, pela outra. Essa foi uma grande surpresa para meu trabalho de campo, cujo rumo se direcionou para a busca de lugares onde minha presença fosse aceita e, mais ainda, onde ela fosse simplesmente possível.

Meu depoimento é sobre um campo onde o silêncio generalizado - quando não a patologização - a respeito de questões de gênero e sexualidade faz com que o nosso lugar de pesquisadoras mulheres seja também invisibilizado e rejeitado de diversas maneiras. Fazer um trabalho de campo solitário, corporalmente excludente, nos vulnerabiliza de formas muito objetivas. Salva-se quem possa, na procura das informações, encontrar contatos e boas experiências em campo. Salva-se quem gravita favoravelmente em torno dos discursos normativos de gênero.

As formas de discriminação baseadas no sexismo, heterossexualidade compulsória e misoginia que definem o espaço aqui descrito não são exclusivas dele. Apesar das especificidades próprias do citado campo, tais traços estão longe de serem exclusivos deste lugar. A situação aqui colocada retrata, em vários pontos, uma realidade que extravasa este centro específico e se espelha no espaço social maior das práticas do turismo ayahuasqueiro localizadas na Amazônia peruana.

\section{BRASIL: CONTEXTO RELIGIOSO}

A segunda narrativa envolve o Santo Daime no Brasil, onde a ayahuasca é regulamentada somente para fins definidos como religiosos. Além dos diversos usos feitos por diferentes povos indígenas da Amazônia Ocidental, as religiões ayahuasqueiras ${ }^{10}$ e as comunidades neo-ayahuasqueiras - modos urbanos, não indígenas e não institucionalizados de uso da bebida (LABATE, 2004) - também fazem parte do cenário ayahuasqueiro do país. O Santo Daime, primeira das religiões ayahuasqueiras, nasceu como um pequeno culto eclético em torno da figura carismática de seu fundador, Raimundo Irineu Serra, e hoje se caracteriza como uma religião global, presente em todos os estados brasileiros e nos diversos continentes (ASSIS, 2017).

Minha pesquisa se desenvolveu entre 2015 e 2019, culminando na minha tese de doutoramento em sociologia (BENEDITO, 2019), na qual apresento a etnografia, realizada em uma comunidade daimista localizada no sul de Minas Gerais, que observou como a comunidade elabora os conceitos de feminino e de masculino.

\footnotetext{
${ }^{10}$ As outras são as também brasileiras Barquinha e União do Vegetal (UDV).
} 
Escolhi estudar o Santo Daime porque eu integrava o grupo como fardada ${ }^{11}$. Assim, posso dizer que meu interesse investigativo veio depois do interesse pessoal pela religião e de minha conversão ao culto. Já foi debatido pela bibliografia especializada (LABATE, 2004; DE ROSE, 2007; ASSIS, 2017; CAMINHA, 2016), que um "posicionamento duplo" como esse não é incomum no campo de estudos das religiões ayahuasqueiras e sua recorrência, inclusive, apoiou a construção de termos como "antropóloga ayahuasqueira" (LABATE, 2004) e "sociólogo ayahuasqueiro" (ASSIS, 2017).

Durante a investigação e no decorrer de 2015 a 2018, participei de 2 retiros de mulheres, 2 rituais de mulheres, 2 feitios, 35 trabalhos de hinário, 5 missas, 15 trabalhos de concentração e 3 trabalhos de cura ${ }^{12}$. Além disso, ainda vivi por 14 meses na comunidade ${ }^{13}$, durante a imersão etnográfica. Apesar de eu fazer parte do grupo, oficialmente, desde 2012 - ou seja, três anos antes do início da pesquisa - a imersão trouxe à tona situações e dados antes invisíveis a mim e destacou outros, de modo muito semelhante ao citado por de Rose (2007).

Mas além de pesquisadora e daimista, eu também sou mulher, e é sobre isso que vou me deter agora. Ser mulher foi tão marcante em minha experiência de pesquisa que fez com que os significados do que é feminino e do que é masculino extravasassem a posição de objeto de pesquisa e definissem minha própria posição em campo. Isso pois, por raríssimas exceções - e a comunidade estudada não é uma delas - o Santo Daime estabelece uma rígida separação ritual, espacial e de trabalho entre homens e mulheres, o que fez com que meu olhar fosse também espacialmente situado pelo campo.

Embora a comunidade seja comandada por um casal, é do homem a posição de liderança política como presidente da igreja e é ele quem, na maior parte das vezes, define os caminhos políticos e rituais que a comunidade deve seguir. As bases cosmológicas do grupo são baseadas nas considerações do líder, que acredita ter descoberto uma nova chave de interpretação do Santo Daime ${ }^{14}$. Inclusive, dentro dessa chave, ele elaborou uma narrativa particular sobre o mito fundacional do culto, comum às demais igrejas.

\footnotetext{
${ }^{11}$ Aqueles que aderem oficialmente ao Santo Daime são fardados e fardadas. Além de uma série de responsabilidades sociais e rituais dentro da religião, essas pessoas usam uniformes femininos e masculinos (as fardas) durante as cerimônias.
}

12 São diversos os tipos de rituais no Santo Daime. Para saber mais sobre os rituais feitos na comunidade estudada, buscar Benedito (2019).

${ }^{13} \mathrm{~A}$ comunidade é composta por uma matriz e por alguns pontos filiados (igrejas menores). Na sede, além da igreja onde os rituais são realizados, das plantações de chacrona e jagube e do espaço para a decocção da ayahuasca - chamada de daime no Santo Daime - existe uma vila de moradores. Foi lá que vivi por 14 meses, participando no cotidiano mais íntimo da comunidade.

${ }^{14}$ Isso não é algo incomum no contexto do campo ayahuasqueiro, no qual líderes legitimam sua posição a partir da criação de algo que é novo - nunca visto (LABATE, 2004). Como líder e como primeiro descobridor dessa nova chave, é ele quem define o que e como os adeptos e adeptas 
O mito narra que foi a Rainha da Floresta - posteriormente reconhecida como a Virgem da Conceição - quem entregou a Raimundo Irineu Serra a missão de fundar o Santo Daime. Segundo o líder da comunidade estudada, esse encontro iniciou uma nova era global, feminina e mariana: a era da mãe. Isso sustenta como o grupo relaciona o feminino e a feminilidade à devoção mariana cristã, que abrange a maternidade, o sofrimento paciente, o sacrifício e o cuidado. Críticas à essa narrativa são vistas como sinais de rebeldia e infelicidade e o culto é observado como uma doutrina baseada em um feminismo "do bem" - em oposição ao feminismo histórico, interpretado como "radical"15 e problemático -, por valorizar o que é quintessencialmente feminino e sagrado: a Virgem Maria ${ }^{16}$.

Outra narrativa do líder que se relaciona ao conceito de feminino é sobre a criação do universo. Segundo ele, o universo foi fundado pela união de uma partícula feminina (a mãe) e outra masculina (o pai) que, reproduzindo-se, criaram tudo quanto existe à sua semelhança: ou feminino ou masculino. Numa classificação binária dos gêneros, as mulheres são relacionadas ao emocional, à intuição, ao cuidado, à sutileza e à passividade, enquanto os homens são relacionados ao racional, à provisão, à força bruta e à atividade. Feminino e masculino são assim postos como identidades primárias e estáveis ${ }^{17}$ e sua performance segundo o conceito de Butler (2003) -, através da separação ritual e cotidiana entre homens e mulheres, é fundamental para produzir a aparência de essencialidade e inevitabilidade dessas identidades.

No salão, nome dado ao espaço onde acontecem os rituais, homens e mulheres ficam em espaços opostos: mulheres à esquerda e homens à direita. O salão é o espaço central da igreja, composto também por um quarto onde é servido daime aos homens (através de uma janelinha na direita) e às mulheres (através de uma janelinha à esquerda) e dois quartos anexos ao salão: o quartinho dos homens e o quartinho das mulheres. Externamente, ainda há um jardim, onde os participantes podem fazer suas purgas ${ }^{18}$, e uma casa onde ficam as crianças e que tem conexão direta apenas com o quarto das mulheres, já

devem estudar. Críticas direcionadas a ele, à sua liderança política ou à tal chave são abafadas ou rebatidas como sinais de falta de respeito, rebeldia ou ilusão.

${ }^{15} \mathrm{~A}$ concepção de feminismo radical na comunidade não corresponde à vertente feminista radical.

${ }^{16}$ O feminismo histórico, que prega a igualdade de direitos e questiona modelos desse tipo, é observado - por parte majoritária do grupo - como uma postura radical, orientada por mulheres agressivas que "queimam sutiãs" e "odeiam os homens".

17 "Se a verdade interna do gênero é uma fabricação, e se o gênero verdadeiro é uma fantasia instituída e inscrita sobre a superfície dos corpos, então parece que os gêneros não podem ser nem verdadeiros nem falsos, mas somente produzidos como efeitos da verdade de um discurso sobre a identidade primária e estável" (BUTLER, 2003, p. 195).

${ }^{18}$ As purgas são concebidas como uma limpeza física e espiritual e fazem parte dos diversos usos da ayahuasca, indígenas e não indígenas. 
que o cuidado da família e das crianças é, a partir dessa divisão essencialista, uma tarefa considerada feminina.

Durante os rituais, as mulheres possuem papéis específicos. São elas que iniciam as orações e os cantos dos hinos (e, por isso, são chamadas de puxadoras). Os homens costumam servir o daime e puxarem os vivas, exclamações de louvor que acontecem em determinados rituais e são respondidas por todos os participantes ${ }^{19}$. Embora tenha acontecido, na comunidade estudada, de mulheres comandarem rituais, servirem o daime e puxarem os vivas, é comum que esses sejam trabalhos masculinos. Já no cotidiano da comunidade, as mulheres são as principais responsáveis pela limpeza e embelezamento do espaço e pelo cuidado das crianças e dos adolescentes. Aos homens, cabe o trabalho de manutenção de infraestrutura.

Quando disse que a experiência de campo me foi importante para destacar certas situações e dados antes invisíveis - ou menos visíveis -, me referia também à observação mais profunda desta divisão. Desde a minha iniciação, estive próxima de um ponto de luz filiado 20 à comunidade e localizado no interior de São Paulo. O ponto é comandado por uma mulher е егa frequentado, naquela época, majoritariamente por mulheres. Por isso, foi somente com a pesquisa já em andamento que descobri o quão incomum é, no Santo Daime, que mulheres sirvam o sacramento ou comandem rituais. Foi também em campo que descobri o quanto a feminilidade e a masculinidade são centrais no grupo e como isso baseia uma divisão sexual do trabalho na vida cotidiana da comunidade e, ainda, a valorização do casamento e da constituição de famílias.

Isso pois, vivendo na comunidade como uma adepta, fui levada a cuidar da cozinha, da organização de festas, de limpeza e organização, pois essas atividades eram destacadas como de minha responsabilidade, como mulher. Além disso, observei a pressão para a reprodução do modelo familiar através do casamento e da gestação, sendo a gestação e a maternidade consideradas como epítome da feminilidade e o casamento como uma emulação da união sagrada que deu origem ao universo.

Em campo senti e refleti sobre os impactos emocionais dessa pressão e, em minha escrita, destaquei como em uma concepção de universo que se divide entre feminino e masculino, baseando-se em corpos sexuado, ignora transexualidades e não conformidades de gênero, pois elas simplesmente rompem com o discurso teológico.

19 Em muitas outras igrejas daimistas, somente os homens podem responder aos vivas. Especificamente no ICEFLU, a questão ainda é foco de debates acalorados entre filiados e filiadas.

${ }^{20}$ Pontos de luz são igrejas menores e ligadas a uma igreja maior. Normalmente, os frequentadores desses pontos, fazem rituais como de concentração e cura nesses lugares e participam dos rituais oficiais e dos festivais na igreja "matriz". 
O desejo não heteronormativo também escapa ao discurso. Cheguei a ouvir em campo a consideração de que homossexuais são pessoas mais promíscuas e que, portanto, podem não se adequar ao culto, cuja centralidade está no casamento monogâmico e reprodutivo ${ }^{21}$. De modo similar ao posto por Rubin (2003), a homossexualidade segue sua normatização - e aceitação - conforme se aproxime do modelo heterossexual, monogâmico e reprodutivo.

A psicóloga Clancy Cavnar (2011), em seu trabalho pioneiro sobre a relação de LGBTQIA+s com a ayahuasca, apontou como a experiência psicodélica e religiosa com a bebida têm potencial para apoiar essas pessoas. Ela inclusive identificou que a experiência extática individual é potente contra a submissão a discursos homofóbicos no cerne de algumas comunidades ayahuasqueiras, caso os participantes venham a se filiar a elas.

Porém, minhas experiências investigativas e religiosas 22 apontaram para um possível limite dessa resistência. Quando me afastei geograficamente e afetivamente de amigos e/ou espaços LGBTQIA+s, por conta do longo período de imersão etnográfica, senti de forma mais pungente os efeitos de uma comunidade que, efetivamente, possui traços profundamente conservadores, que valoriza feminilidades e afetividades normatizadas e que não possui, em suas bases teológicas, espaço para as diferenças.

Realizar campo nesses contextos pode gerar sofrimento - especialmente se tratando da comunidade religiosa de iniciação da pesquisadora. É por isso que reflexões como essa são importantes, pois elas podem ilustrar cenários que podem se apresentar em outros campos de pesquisa, apontam para modos menos custosos de se fazer uma pesquisa nesses lugares e descrevem situações que foram, por vezes, não problematizadas em outras pesquisas, destacando-se as potencialidades de investigações feitas por mulheres.

\section{RECOMENDAÇÕES PARA FUTURAS ETNÓGRAFAS}

A partir do relato destes cenários, apresentaremos algumas propostas que podem tornar o fazer etnográfico no campo ayahuasqueiro menos árduo para as etnógrafas. Tais recomendações se orientam à diversidade de espaços ayahuasqueiros existentes na América Latina, sejam eles religiosos, tradicionais, neo-xamânicos ou terapêuticos - ou uma combinação deles:

- Exercite cotidianamente o confronto com uma visão romantizada sobre a ayahuasca e seus/suas mestres, xamãs, padrinhos e madrinhas. Tal romantização está presente

\footnotetext{
${ }^{21}$ Embora haja casos de líderes daimistas que possuem mais de uma esposa.

22 Que também envolveu o contato com outros LGBTQI+s de círculos ayahuasqueiros em cidades centrais e do interior do país.
} 
em todas as dimensões do campo, desde a literatura especializada às experiências mais cotidianas. Nesta visão romantizada, tais líderes são vistos como pessoas excepcionais, cuja ação é pouco discutida socialmente - o que pode dificultar tanto a crítica investigativa quanto o reconhecimento de abusos;

- Evite, tanto quanto possível, tomar como objeto o próprio campo de iniciação religiosa. Tal escolha envolve um profundo trabalho emocional, pois demanda a observação cuidadosa e a crítica de instituições, líderes e sistemas de pensamento de algo afetivamente próximo e íntimo;

- Um caminho sugerido para a realização de pesquisas etnográficas marcada pelo duplo posicionamento consiste em dar preferência por estudar um grupo que não o de sua iniciação - seja outra comunidade da mesma prática ou um grupo diferente;

- No caso de se escolher o campo de iniciação como objeto, é importante considerar algumas de suas potencialidades, como a facilidade para se observar conflitos internos e a própria disposição para a criação de laços de confiança, já que o campo ayahuasqueiro é cindido por conflitos internos que criam uma aura de desconfiança de um grupo sobre outros;

- Saiba que o campo ayahuasqueiro é um espaço potencial para a produção de conhecimento, mas que, como em qualquer outro contexto - religioso ou não também de é um espaço potencial de abusos. Saiba que, inclusive, tais abusos podem ser de caráter sexual;

- Caso não conheça previamente a comunidade que pretende estudar, se informe através de colegas - especialmente mulheres - sobre ela e as particularidades de uma estadia lá;

- Privilegie fazer entrevistas em locais públicos e busque ir até elas acompanhada de outra pesquisadora, colega ou amiga;

- Elabore estratégias para consensuar formas de trabalho de campo articuladas além do individual: crie instâncias de produção de conhecimento com outras pessoas particularmente, outras mulheres. Isso, além de ser uma resposta efetiva contra o isolamento em campo, facilita o exercício da escrita e análise de experiências socialmente compartilhadas;

- Não hesite em dar fim a uma situação que a incomoda, mesmo que essa decisão interfira nos objetivos desejados por você para a sua pesquisa. A vivência de uma mudança no rumo faz parte intrínseca de toda pesquisa de tipo qualitativo.

- Quando escolher tomar ayahuasca, busque fazê-lo em espaços seguros e de confiança, evitando os rituais "especialmente designados" por outros para você. Tais rituais podem facilitar situações de abuso; 
- Especificamente sobre o risco de abuso sexual, saiba que a ayahuasca pode estimular a libido não somente das outras pessoas, mas a sua também. Esteja certa do que quer que aconteça e prepare-se para isso;

- Se você observar um caso de abuso sexual ou então de violência de gênero, busque um local seguro para denunciar. Procure organizações de mulheres que sejam sensíveis a esse tipo de experiência e evite o acolhimento em contextos religiosos ou rígidos que sejam contra o consumo de psicoativos, pois isso pode aprofundar a ferida;

- No artesanato de seu trabalho final, você pode colocar ou não o nome das pessoas que cometeram abusos verbais, físicos ou sexuais durante sua pesquisa;

- Embora a bibliografia especializada seja quase unânime em dizer que é necessário tomar ayahuasca para fazer trabalhos sobre o tema, saiba que você pode, em qualquer momento da pesquisa, escolher como, quando e se quer ou não tomar a bebida. Nem todas as pesquisas sobre ayahuasca precisam estar fundadas em perspectivas auto-etnogáficas ou fenomenológicas;

- Trazer à tona situações de abuso não é somente um exercício terapêutico, mas também é uma prática de crescimento e posicionamento profissional. Esse exercício pode, inclusive, vir a se tornar um dado importante em sua pesquisa e, não bastando isso, orientar as empreitadas de futuras pesquisadoras e pesquisadores;

- Apesar das dores da revitimização, denunciar uma injustiça irá certamente colaborar com a visibilização de situações de opressão, contribuindo, de forma direta ou indireta, a melhorar as condições de vida de mulheres e outros grupos vulneráveis, tais como comunidade LGBTQIA+, pessoas com deficiência, crianças, idosos, pessoas em situação de adoecimento mental, etc. que façam parte/transitem por estes grupos.

\section{CONSIDERAÇÕES FINAIS}

O que será que vimos que os pesquisadores homens não foram capazes de observar? Os aspectos da nossa pesquisa, que em algum momento vivenciamos como uma limitação a ser ocultada, são observados aqui como uma potencialidade. Com isso, afirmamos a ideia de que nosso pertencimento a lugares vulneráveis pode ser transformado na expressão direta de experiências de opressão dentro da própria produção do saber acadêmico, e de que tais experiências têm um valor metodológico e pedagógico. Nosso interesse é o de fomentar uma discussão ética, crítica e localizada da produção do conhecimento dentro do campo ayahuasqueiro. 
Brasil, Peru: nossos campos estão lá e os interditos existem. Por uma parte, sabemos que precisamos estar melhor preparadas para afrontá-los. Pela outra, tensionando o cânone de discursos antropológicos que se apóiam no conforto das normas fundadas na desigualdade de gênero e na LGBTQIA+fobia, apontamos para que a reflexão metodológica e pedagógica sobre as experiências negligenciadas em campo colabore não somente para compreender melhor esses mundos, mas também para transformá-los. Colocamos assim como urgente o tratamento das desigualdades de gênero, da discriminação sexual e outras violações dos direitos humanos, que não são pouco frequentes nos cenários e nas pesquisas aqui descritos.

\section{REFERÊNCIAS}

ASSIS, Glauber Loures de. A Religião of the Floresta: apontamentos sociológicos em direção a uma genealogia do Santo Daime e seu processo de diáspora. Tese de Doutorado do Programa de PósGraduação em Sociologia, Universidade Federal de Minas Gerais: Belo Horizonte, 2017.

BENEDITO, Camila de Pieri. Maria que me ensina a ser mulher: Gênero e religião no Santo Daime. Tese de Doutorado do Programa de Pós-Graduação em Sociologia, Universidade Federal de São Carlos: São Carlos, 2019.

BUTLER, Judith. Problemas de Gênero: Feminismo e Subversão da Identidade. Rio de Janeiro: Ed. Civilização Brasileira, 2003.

CAMINHA, P. Examine a consciência: 0 acesso ao conhecimento na doutrina do Santo Daime. Dissertação de Mestrado do Programa de Pós-Graduação em Ciências Sociais da Universidade Federal de Juiz de Fora: Juiz de Fora, 2016.

CAVNAR, C. The effects of participation in ayahuasca rituals on gays' and lesbians' self perception. Dissertação de Mestrado em Psicologia da Kennedy University: Pleasant Hill, 2011.

CHACRUNA. Guia da Comunidade Ayahuasqueira para Conscientização sobre Abuso Sexual do Instituto Chacruna. https://chacruna.net/wp-content/uploads/2019/06/Chacruna-Sexual-Awareness-GuidelinesPortuguese.pdf

COLPRON, Anne Marie. Monopólio masculino do xamanismo amazônico: o contra-exemplo das mulheres-xamã Shipibo-Conibo. MANA, v. 11, n. 1, p. 95-128, 2005.

DE ROSE, Isabel. Entre colinas verdes: Trabalhos espirituais, plantas e culinária. Reflexões sobre experiências de campo numa comunidade do Santo Daime. In: ONETTI, A. de L.; FLEISCHER, S. (Orgs.). Entre saias justas e jogos de cintura: gênero e etnografia na antropologia brasileira recente. Florianópolis: Editora Mulheres/EDUNISC, 2007.

DEMANGE, François. Amazonian vegetalismo. A study of the healing power of chants in Tarapoto, Peru. M.A. in Social Sciences: University of East London, 2002. 
ECHAZÚ BÖSCHEMEIER, Ana Gretel. Corpo de planta. Terapias e magias dxs curiosxs da baixa Amazônia do Peru, sob uma perspectiva situada de gênero e de saúde popular. Tese de Doutorado em Antropologia Social, Departamento de Antropologia da Universidade de Braślia: Braślia, 2015.

. Men, shaman and ayahuasca as overlapping clichés in Peruvian vegetalismo. In: LABATE, B.;

CAVNAR, C. The Expanding World Ayahuasca Diaspora: Appropriation, integration and legislation. Oxford: Routledge, 2018. p. 137-156.

ECHAZÚ BÖSCHEMEIER, Ana Gretel; BENEDITO, Camila de Pieri. Violência Sexual e Políticas de Gênero no Campo Ayahuasqueiro: Uma visão brasileira. Disponível em: https://www.bialabate.net/news/violencia-sexual-e-politicas-de-genero-no-campo-ayahuasqueiro-umaperspectiva-brasileira, 2018a.

. Sexual Assault and Gender Politics in Ayahuasca Traditions: A View from Brazil. Em: https://chacruna.net/sexual-assault-and-gender-politics-in-ayahuasca-traditions-a-view-from-brazil/, 2018b.

. Violencia Sexual y Políticas de Género en el Campo Ayahuasquero: Una visión desde Brasil. Disponível em: https://www.bialabate.net/news/violencia-sexual-e-politicas-de-genero-no-campoayahuasqueiro-uma-perspectiva-brasileira, 2018c.

FERREIRA, Claudio A. 0 Vinho das Almas: xamanismo e cristianismo no Santo Daime. Dissertação (Mestrado) - Programa de Pós-Graduação em Ciências da Religião, Pontifícia Universidade Católica de São Paulo, São Paulo, 2008.

GEARIN, Alex; LABATE, Beatriz. "“'La Dieta". Ayahuasca and the Western reinvention of indigenous Amazonian food shamanism". In: CAVNAR, Clancy. The Expanding World Ayahuasca Diaspora: Appropriation, Integration and Legislation. London: Routledge, 2018. p. 177-197.

GOULART, Sandra Lúcia. Contrastes e Continuidades em uma Tradição Amazônica: as religiões da ayahuasca. Tese (Doutorado) - Programa de Pós-Graduação em Antropologia, Universidade de Campinas, Campinas, 2004.

LABATE, Beatriz Caiuby. A reinvenção do uso da ayahuasca nos centros urbanos. Campinas-SP: Mercado de Letras; São Paulo: FAPESP, 2004.

. Queering Psychedelics. 01-07-2019. In: https://chacruna.net/queering-psychedelics/. Acesso em 04-08-2019.

MERCANTE, Marcelo S. A ayahuasca e o tratamento da dependência. Mana, v. 19, n. 3, p. 529-558, 2013.

PLATERO, Ligia Duque. La dieta del muká como transposición de jerarquías entre los Yawanawá en Brasil. 16-02-2018. In: https://drogaspoliticacultura.net/psa/la-dieta-del-muka-transposicion-jerarquiaslos-yawanawa-en-brasil/. Acesso em 06-12-2019.

RIBEIRO, Djamila. 0 que é lugar de fala?. Belo Horizonte: Letramento, 2017.

RUBIN, Gayle. Pensando sobre sexo. Mimeo, 2003.

Recebido em 6 de agosto de 2019. Aprovado em 5 de novembro de 2019. 